\title{
What Factors are Associated With Quality Of Life, Pain Interference, Anxiety, and Depression in Patients With Metastatic Bone Disease?
}

\author{
Q. M. J. van der Vliet BSc, N. R. Paulino Pereira MD $®$, S. J. Janssen MD, \\ F. J. Hornicek MD, MS, PhD, M. L. Ferrone MD, J. A. M. Bramer MD, PhD, \\ C. N. van Dijk MD, PhD, J. H. Schwab MD, MS
}

Received: 22 June 2016/Accepted: 4 October 2016/Published online: 17 October 2016

(C) The Association of Bone and Joint Surgeons ( 2016

\begin{abstract}
Background It would be helpful for the decision-making process of patients with metastatic bone disease to understand which patients are at risk for worse quality of life (QOL), pain, anxiety, and depression. Normative data, and where these stand compared with general population scores, can be useful to compare and interpret results of similar patients or patient groups, but to our knowledge, there are no such robust data.
\end{abstract}

One of the authors certifies that he (SJJ), or a member of his or her immediate family, has or may receive payments or benefits, during the study period, an amount of less than USD 10,000 from the Anna Foundation (Oegstgeest, The Netherlands), an amount of less than USD 10,000 from the De Drie Lichten Foundation (Hilversum, The Netherlands), an amount of less than USD 10,000 from the KWF Kankerbestrijding (Amsterdam, The Netherlands), and an amount of less than USD 10,000 from the Michael van Vloten Foundation (Rotterdam, The Netherlands).

All ICMJE Conflict of Interest Forms for authors and Clinical Orthopaedics and Related Research ${ }^{\circledR}$ editors and board members are on file with the publication and can be viewed on request.

Each author certifies that his or her institution approved the human protocol for this investigation, that all investigations were conducted in conformity with ethical principles of research, and that informed consent for participation in the study was obtained.

This study was performed at Massachusetts General Hospital \& Brigham and Women's Hospital, Boston, MA, USA

Electronic supplementary material The online version of this article (doi:10.1007/s11999-016-5118-3) contains supplementary material, which is available to authorized users.

Q. M. J. van der Vliet, N. R. Paulino Pereira, S. J. Janssen, F. J. Hornicek, J. H. Schwab

Department of Orthopaedic Surgery, Orthopaedic Oncology Service, Massachusetts General Hospital, Harvard Medical

School, Boston, MA, USA
Questions/Purposes We wished (1) to assess what factors are independently associated with QOL, pain interference, anxiety, and depression in patients with metastatic bone disease, and (2) to compare these outcomes with general US population values.

Methods Between November 2011 and February 2015, 859 patients with metastatic bone disease presented to our orthopaedic oncology clinic; 202 (24\%) were included as they completed the EuroQOL-5 Dimension (EQ-5D ${ }^{\mathrm{TM}}$ ), PROMIS $^{\mathbb{R}}$ Pain Interference, PROMIS ${ }^{\circledR}$ Anxiety, and PROMIS ${ }^{\circledR}$ Depression questionnaires as part of a quality improvement program. We did not record reasons for not responding and found no differences between survey respondents and nonrespondents in terms of age (63 versus 64 years; $\mathrm{p}=0.916)$, gender $(51 \%$ men versus $47 \%$ men; $\mathrm{p}=0.228)$, and race $(91 \%$ white versus $88 \%$ white; $\mathrm{p}=$ 0.306 ), but survey responders were more likely to be married or living with a partner $(72 \%$, versus $62 \%$; $\mathrm{p}=$ 0.001). We assessed risk factors for QOL, pain interference, anxiety, and depression using multivariable linear regression analysis. We used the one-sample signed rank test to assess whether scores differed from US population averages drawn from earlier large epidemiologic studies.

\section{L. Ferrone}

Department of Orthopaedic Surgery, Orthopaedic Oncology Service, Brigham and Women's Hospital, Harvard Medical School, Boston, MA, USA

J. A. M. Bramer, C. N. van Dijk

Department of Orthopaedic Surgery, Academic Medical Center, University of Amsterdam, Amsterdam, The Netherlands

N. R. Paulino Pereira $(\square)$

Massachusetts General Hospital, Room 3.946, Yawkey Building,

55 Fruit Street, Boston, MA 02114, USA

e-mail: nunorui.pp@gmail.com 
Results Younger age $(\beta$ regression coefficient $[\beta],<0.01$; 95\% CI, 0.00-0.01; $\mathrm{p}=0.041)$, smoking $(\beta,-0.12 ; 95 \%$ $\mathrm{CI},-0.22$ to $-0.01 ; \mathrm{p}=0.026)$, pathologic fracture $(\beta$, $-0.10 ; 95 \% \mathrm{CI},-0.18$ to $-0.02 ; \mathrm{p}=0.012)$, and being unemployed $(\beta,-0.09 ; 95 \% \mathrm{CI},-0.17$ to $-0.02 ; \mathrm{p}=$ 0.017 ) were associated with worse QOL. Current smoking status was associated with more pain interference $(\beta, 6.0$; $95 \% \mathrm{CI}, 1.6-11 ; \mathrm{p}=0.008)$. Poor-prognosis cancers $(\beta$, $3.8 ; 95 \% \mathrm{CI}, 0.37-7.2 ; \mathrm{p}=0.030)$, and pathologic fracture $(\beta, 6.3 ; 95 \% \mathrm{CI}, 2.5-7.2 ; \mathrm{p}=0.001)$ were associated with more anxiety. Being single $(\beta, 5.9 ; 95 \% \mathrm{CI}, 0.83-11 ; \mathrm{p}=$ $0.023)$, and pathologic fracture $(\beta, 4.4 ; 95 \% \mathrm{CI}, 0.8-8.0$; $\mathrm{p}=0.017)$ were associated with depression. QOL scores ( 0.68 versus $0.85 ; \mathrm{p}<0.001)$, pain interference scores $(65$ versus 50; $\mathrm{p}<0.001$ ), and anxiety scores (53 versus 50; $\mathrm{p}=$ 0.011) were worse for patients with bone metastases compared with general US population values, whereas depression scores were comparable (48 versus $50 ; \mathrm{p}=$ 0.171).

Conclusions Impending pathologic fractures should be treated promptly to prevent deterioration in QOL, anxiety, and depression. Our normative data can be used to compare and interpret results of similar patients or patient groups. Future studies could focus on specific cancers metastasizing to the bone, to further understand which patients are at risk for worse patient-reported outcomes.

Level of evidence Level III, prognostic study.

\section{Introduction}

The main goal when treating patients with metastatic bone disease is to preserve or even improve quality of life (QOL) [7, 29]. Questionnaires that measure QOL can quantify treatment effectiveness and guide clinical decision-making [7, 18, 30]. Several studies identified risk factors for QOL in patients with metastatic bone disease; [8, 25, 28, 29] however, these often were measured after specific treatment(s), and therefore do not represent QOL for all patients with metastatic bone disease.

It would be useful to more fully understand which patients are at risk for worse QOL, pain, anxiety, and depression, so that deterioration for these patients can be anticipated and potentially overcome with medical treatment. In addition, it is helpful to have normative data for patients with metastatic bone disease to be able to compare and interpret results of similar patients or patient groups. To our knowledge, there are no rigorous sources to date that provide such information.

Therefore, we sought to identify factors independently associated with QOL, pain interference, anxiety, and depression. Secondly, we compared these patient-reported outcome scores with general US population scores.

\section{Patients and Methods}

Study Design, Setting, and Subjects

After approval by the institutional review board of Massachusetts General Hospital, we analyzed prospectively gathered patient-reported outcome data of patients with bone metastases from solid tumors, myeloma, or lymphoma, who presented to our clinic between November 1, 2011 and February 1, 2015. As part of a quality improvement program, patients completed the following questionnaires before visiting the surgeon at our orthopaedic oncology service since November 2011: the EuroQOL 5 Dimension Questionnaire (EQ-5D ${ }^{\mathrm{TM}}$ ), PatientReported Outcomes Measurement Information System (PROMIS ${ }^{\circledR}$ ) Pain Interference, PROMIS ${ }^{\circledR}$ Anxiety, and PROMIS ${ }^{\circledR}$ Depression.

Through the information system (Research Patient Data Registry) from Massachusetts General Hospital, we identified 16,769 unique patients who received the ICD-9 code for "Secondary malignant neoplasm of bone and bone marrow" between February 1990 and February 2015; 1714 of those patients were seen at our orthopaedic oncology clinic, of whom 859 were seen during the period of the quality improvement program (November 2011 to February 2015). Of the 859 potentially eligible patients, 202 (24\%) completed the survey and 657 (76\%) did not (Fig. 1). We were unable to track reasons for nonparticipation, but we did analyze differences in baseline characteristics between the surveyed and nonsurveyed patients. There were no differences in age (63 versus 64 years; $\mathrm{p}=0.916)$, sex $(51 \%$ men versus $47 \%$ men; $\mathrm{p}=$ $0.228)$, and race (91\% white versus $88 \%$ white; $\mathrm{p}=0.306)$, but survey responders were more likely to be married or living with a partner (72\% versus $62 \%$; $\mathrm{p}=0.001)$ (Appendix 1. Supplemental material is available with the online version of $\left.C O R R^{\circledR}\right)$. We therefore believe that our results can be generalized to the overall population of patients with bone metastasis presenting to an orthopaedic oncology clinic.

Questionnaires were completed through the REDCap (Research Electronic Data Capture) data capture tool on a tablet computer [14]. We included the first completed survey in the case patients had completed surveys multiple times, as not to violate the statistical assumption of independence. 


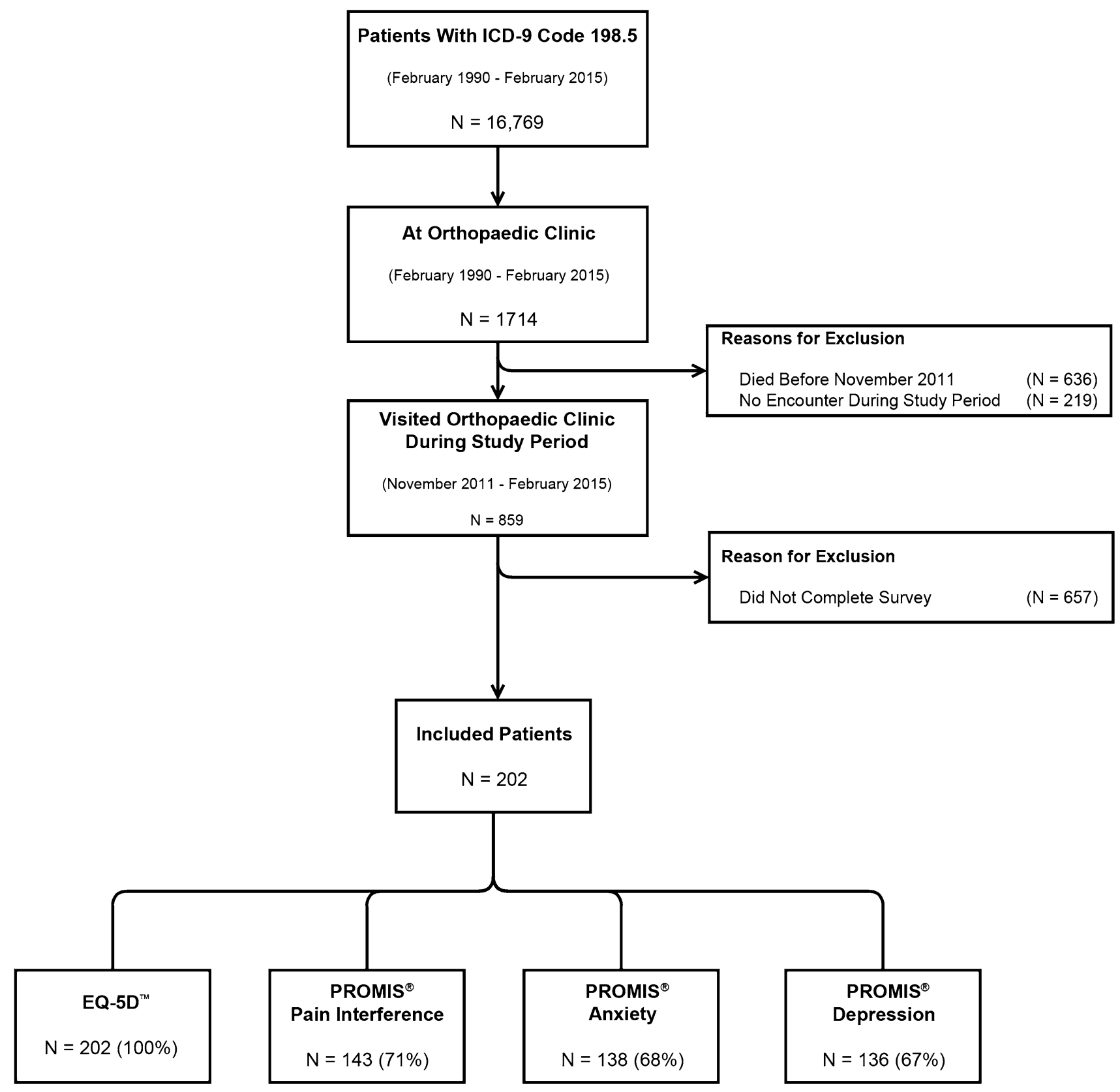

Fig. 1 This flow chart shows the selection procedure of the included cohort. The ICD-9 code 198.5 corresponds to "Secondary malignant neoplasm of bone and bone marrow"

Outcome Measures and Explanatory Variables

Our outcome measures were (1) QOL, as measured with the EQ-5D ${ }^{\mathrm{TM}}$ questionnaire (completed by all patients), (2) how pain interfered with physical function as measured with the PROMIS ${ }^{\circledR}$ Pain Interference questionnaire (completed by $143 ; 71 \%$ ), (3) anxiety as measured with the PROMIS ${ }^{\circledR}$ Anxiety questionnaire (completed by 138; $68 \%$ ), and (4) depression as measured with the PROMIS ${ }^{\circledR}$ Depression questionnaire (completed by 136; 67\%). The latter three questionnaires were not completed by all patients as these were introduced to the quality improvement program at a later time (August 1, 2012). We assessed baseline differences between patients who did not complete a PROMIS ${ }^{\circledR}$ questionnaire $(\mathrm{n}=56)$, and those who did $(\mathrm{n}=146)$. There were no differences in median age (62 versus 64 years; $p=0.972)$, sex $(46 \%$ male versus $53 \%$ male; $p=0.432)$, marital status $(73 \%$ married versus $72 \%$ married; $\mathrm{p}=0.271$ ), median Charlson Comorbidity Index (6 versus $6 ; \mathrm{p}=0.806)$, pathologic fracture $(27 \%$ versus $29 \% ; p=0.862)$, or previous surgery $(14 \%$ versus $8.9 \% ; \mathrm{p}=0.304)$. 
The EQ-5D ${ }^{\mathrm{TM}}-3 \mathrm{~L}$ questionnaire covers five dimensions (mobility, self-care, usual activities, pain/discomfort, and anxiety/depression), and each dimension is divided into three levels (no problems, moderate problems, or extreme problems). The EQ-5D ${ }^{\mathrm{TM}}$ describes 245 unique health states [24]. Fryback et al. [10] obtained age-by-gender EQ$5 \mathrm{D}^{\mathrm{TM}}$ norms for adults in the US; we compared the EQ$5 \mathrm{D}^{\mathrm{TM}}$ scores to the value of 0.85 , based on the age of our study participants.

The PROMIS ${ }^{\circledR}$ was established by the National Institutes of Health $(\mathrm{NIH})$ to develop standardized item banks to assess physical, mental, and social well-being in the medical field. The PROMIS ${ }^{\circledR}$ Pain Interference item bank (six items) assesses the extent to which pain interferes with functioning. The PROMIS ${ }^{\circledR}$ Anxiety questionnaire (six items) includes questions regarding fear, anxious misery, hyperarousal, and somatic symptoms related to arousal. The PROMIS ${ }^{\circledR}$ Depression questionnaire (six items) focuses on negative mood, decrease in positive affect, information-processing deficits, negative views of self, and negative social cognition. All PROMIS ${ }^{\circledR}$ scores have a general US population-based mean T-score of 50; these scores are not adjusted by age or gender [5].

Two researchers (QvdV, SJJ) extracted the following explanatory variables from medical records in a retrospective manner, as these were known or suggested to be associated with patient-reported outcomes [8, 25, 28, 29]: age, sex, race, employment status, marital status, smoking status, comorbidity status, BMI in $\mathrm{kg} / \mathrm{m}^{2}$, primary tumor type, time between diagnosis of primary tumor and survey, time between diagnosis of metastatic disease and survey, location of the bone metastasis leading to the consultation (spine, lower extremity, upper extremity, pelvis, multiple, and other locations), current radiotherapy, current systemic therapy, prior surgery for bone metastasis, pathologic fracture (an impending pathologic fracture was not considered a fracture), presence of other bone metastases, and presence of visceral or brain metastases.

We assessed the comorbidity status using a modified Charlson Comorbidity Index; this is an index weighting 12 comorbidities known to be associated with 10-year survival [6]. We used a modified Charlson Comorbidity Index calculated by a previously described algorithm based on ICD9 codes [23]. The presence of additional comorbidities was based on the modified Charlson Comorbidity Index and defined as the presence of conditions other than metastatic bone disease, multiple myeloma, or lymphoma. We extracted BMI closest to completion of the survey and omitted values recorded longer than 90 days before the survey. "Former smoker" was defined as stopped smoking at least 1 year before the survey. Based on a study by Katagiri et al. [17], we categorized primary tumors as those with a relatively good prognosis (breast, kidney, prostate, thyroid, myeloma, and lymphoma), and those with a relatively poor prognosis (all other tumor types). Systemic therapy was defined as any type of hormonal therapy, chemotherapy, or immunotherapy for the primary cancer. The fracture status, presence of other bone metastases, and visceral metastases were derived from radiology reports.

An independent researcher (NRPP) crosschecked a random $10 \%$ sample of the retrospectively collected data to ensure a robust database; there were less than $5 \%$ inconsistencies overall, and there were no repeated inconsistencies within one variable.

\section{Statistical Analysis}

Continuous variables were presented as medians with interquartile ranges (IQR), and categorical variables as frequencies with percentages. Data were analyzed using nonparametric tests, as histograms suggested nonnormal distribution of continuous variables.

We did an exploratory bivariate analysis to assess differences in outcome measures using the Mann-Whitney U test for dichotomous explanatory variables, Kruskal-Wallis test for categorical explanatory variables, and Spearman's rank correlation coefficient for continuous explanatory variables. We used stepwise backward multivariable linear regression analysis-retaining variables with a $\mathrm{p}$ value less than 0.10 - to assess if explanatory variables (as identified by the bivariate analyses) were independently associated with the outcome measures.

We used the one-sample signed rank test to assess whether scores differed from general US population averages.

All statistical analyses were performed with STATA ${ }^{\circledR}$ 13.0 (StataCorp LP, College Station, TX, USA), and twotailed $\mathrm{p}$ values less than 0.05 were considered significant.

\section{Patient Demographics}

The study population consisted of $104(51 \%)$ men and 98 (49\%) women, with a median age of 63 years (range, 27 89 years) (Table 1). Lung cancer was the most common primary cancer $(35 ; 17 \%)$, followed by breast cancer $(33$; $16 \%)$, and multiple myeloma $(33 ; 16 \%)$. The most common location for a bone lesion was the spine $(72 ; 36 \%)$, and $57(28 \%)$ patients presented with a pathologic fracture. Twenty-one (10\%) patients had undergone prior surgery for their metastatic bone lesion(s), with a median of 132 days (IQR, 23-520 days; range, 2-1617 days) between the surgery and survey completion. Seventy-nine (39\%) were being treated with systemic therapy, and nine $(4 \%)$ were receiving radiotherapy for their bone lesion(s) at the time of completing the survey. 
Table 1. Baseline characteristics of 202 patients

\begin{tabular}{|c|c|c|}
\hline Characteristic & Median & Interquartile range \\
\hline Age (years) & 63 & $54-72$ \\
\hline Modified Charlson Comorbidity Index* & 6.0 & $6.0-8.0$ \\
\hline BMI $\left(\mathrm{kg} / \mathrm{m}^{2}\right)^{*}$ & 27 & 24-31 \\
\hline Time between diagnosis of primary tumor and survey (months)* & 26 & $4.1-78$ \\
\hline \multirow[t]{2}{*}{ Time between diagnosis of metastatic disease and survey (months)* } & 7.4 & $0.4-34$ \\
\hline & Number & $\%$ \\
\hline Men & 104 & 51 \\
\hline White race* & 174 & 91 \\
\hline Additional comorbidities $*^{\dagger}$ & 94 & 47 \\
\hline \multicolumn{3}{|l|}{ Employment status* } \\
\hline Employed & 79 & 40 \\
\hline Unemployed & 118 & 60 \\
\hline \multicolumn{3}{|l|}{ Marital status* } \\
\hline Married/living with partner & 144 & 72 \\
\hline Separated/divorced/widowed & 35 & 18 \\
\hline Single & 21 & 11 \\
\hline \multicolumn{3}{|l|}{ Smoking status* } \\
\hline Never smoked & 79 & 41 \\
\hline Former smoker ${ }^{*}$ & 81 & 42 \\
\hline Current smoker & 35 & 18 \\
\hline \multicolumn{3}{|l|}{ Primary tumor type } \\
\hline Lung & 35 & 17 \\
\hline Breast & 33 & 16 \\
\hline Multiple myeloma & 33 & 16 \\
\hline Kidney & 28 & 14 \\
\hline Prostate & 13 & 6 \\
\hline Other/unknown ${ }^{\S}$ & 60 & 30 \\
\hline \multicolumn{3}{|l|}{ Location of presenting metastasis } \\
\hline Spine & 72 & 36 \\
\hline Lower extremity & 40 & 20 \\
\hline Upper extremity & 31 & 15 \\
\hline Pelvis & 27 & 13 \\
\hline Multiple & 30 & 15 \\
\hline Other" & 2 & 1 \\
\hline Current radiotherapy & 9 & 4 \\
\hline Current systemic therapy & 79 & 39 \\
\hline Prior surgery for bone metastasis & 21 & 10 \\
\hline Pathologic fracture & 57 & 28 \\
\hline Multiple bone metastases & 127 & 63 \\
\hline Lung/liver/adrenal/brain metastases & 81 & 40 \\
\hline
\end{tabular}

*Modified Charlson Comorbidity Index was available for 200 patients (99\%), BMI was available for 198 patients (98\%), race was available for 191 patients (95\%), additional comorbidities were available for 200 patients (99\%), employment status was available for 197 patients (98\%), marital status was available for 200 patients (99\%), smoking status was available for 195 patients (97\%), time between diagnosis of primary tumor and survey was available for 193 patients (96\%), and time between diagnosis of metastatic disease and survey was available for 196 patients (97\%); "based on any additional comorbidity in addition to the metastatic disease score following the Charlson Comorbidity Index; ${ }^{*}$ quit at least 1 year before survey; ${ }^{\S}$ thyroid $(n=8)$, lymphoma $(n=6)$, colorectal $(n=6)$, adenocarcinoma $(n=6)$, neuroendocrine $(n=5)$, esophageal $(n=4)$, melanoma $(n=3)$, liver $(n=3)$, bladder $(n=2)$, endometrial $(n=2)$, ovarian $(n=1)$, and pancreatic $(n=1)$; "rib $(n=1)$, occipital condyle $(\mathrm{n}=1)$. 
Table 2. Multivariable linear regression analysis assessing factors independently associated with patient-reported outcomes

\begin{tabular}{|c|c|c|c|}
\hline Explanatory variables per questionnaire & $\beta$ regression coefficient $(95 \% \mathrm{CI})$ & Standard error & $\mathrm{p}$ Value \\
\hline \multicolumn{4}{|l|}{$\mathrm{EQ}-5 \mathrm{D}^{\mathrm{TM}}$ index } \\
\hline Age (in years) & $<0.01(0.00-0.01)$ & 0.001 & $0.041^{\oplus}$ \\
\hline \multicolumn{4}{|l|}{ Smoking status* } \\
\hline Never smoked & Reference & & \\
\hline Former smoker $^{\dagger}$ & $-0.05(-0.13$ to 0.03$)$ & 0.04 & 0.252 \\
\hline Current smoker & $-0.12(-0.22$ to -0.01$)$ & 0.05 & $0.026^{\oplus}$ \\
\hline \multicolumn{4}{|l|}{ Pathologic fracture } \\
\hline No & Reference & & \\
\hline Yes & $-0.10(-0.18$ to -0.02$)$ & 0.04 & $0.012^{\top}$ \\
\hline \multicolumn{4}{|l|}{ Employment status* } \\
\hline Employed & Reference & & \\
\hline Unemployed & $-0.09(-0.17$ to -0.02$)$ & 0.04 & $0.017^{\top}$ \\
\hline \multicolumn{4}{|l|}{ PROMIS ${ }^{\circledR}$ Pain Interference } \\
\hline \multicolumn{4}{|l|}{ Smoking status* } \\
\hline Never smoked & Reference & & \\
\hline Former smoker ${ }^{\dagger}$ & $3.1(-0.37$ to 6.7$)$ & 1.72 & 0.080 \\
\hline Current smoker & $6.0(1.6-11)$ & 2.25 & $0.008^{\top}$ \\
\hline \multicolumn{4}{|l|}{ PROMIS ${ }^{\circledR}$ Anxiety } \\
\hline \multicolumn{4}{|l|}{ Primary tumor type } \\
\hline Good prognosis & Reference & & \\
\hline Poor prognosis & $3.8(0.37-7.2)$ & 1.73 & $0.030^{\top}$ \\
\hline \multicolumn{4}{|l|}{ Pathologic fracture } \\
\hline No & Reference & & \\
\hline Yes & $6.3(2.5-7.2)$ & 1.90 & $0.001^{\top}$ \\
\hline \multicolumn{4}{|l|}{ PROMIS ${ }^{\circledR}$ Depression } \\
\hline \multicolumn{4}{|l|}{ Marital status* } \\
\hline Married/living with partner & Reference & & \\
\hline Separated/divorced/widowed & $0.53(-4.0$ to 5.0$)$ & 2.27 & 0.817 \\
\hline Single & $5.9(0.83-11)$ & 2.54 & $0.023^{\top}$ \\
\hline \multicolumn{4}{|l|}{ Pathologic fracture } \\
\hline No & Reference & & \\
\hline Yes & $4.4(0.8-8.0)$ & 1.82 & $0.017^{\oplus}$ \\
\hline
\end{tabular}

Two-tailed $\mathrm{p}$ value less than 0.05 ; adjusted $\mathrm{R}$ squared values for the multivariate analyses were 0.0586 for the $\mathrm{EQ}-5 \mathrm{D}^{\mathrm{TM}}, 0.0407$ for the PROMIS ${ }^{\circledR}$ Pain Interference, 0.0902 for the PROMIS ${ }^{\circledR}$ Anxiety, and 0.0632 for the PROMIS ${ }^{\circledR}$ Depression; *marital status was available for 200 patients $(99 \%)$; ${ }^{\dagger}$ quit at least one year before survey; ${ }^{\star}$ primary tumor type with good prognosis includes breast, kidney, prostate, thyroid, myeloma and lymphoma, and with poor prognosis includes all other tumor types; EQ-5D ${ }^{\mathrm{TM}}=$ EuroQol 5 Dimension Questionnaire; PROMIS ${ }^{\circledR}=$ Patient-Reported Outcomes Measurement Information System.

\section{Results}

\section{Factors Associated With Worse QOL}

After controlling for relevant confounding variables, we found that younger age ( $\beta$ regression coefficient $[\beta]$, $<0.01 ; 95 \% \mathrm{CI}, 0.00-0.01 ; \mathrm{p}=0.041)$, current smoking status $(\beta,-0.12 ; 95 \% \mathrm{CI},-0.22$ to $-0.01 ; \mathrm{p}=0.026)$, pathologic fracture $(\beta,-0.10 ; 95 \% \mathrm{CI},-0.18$ to $-0.02 ; \mathrm{p}$ $=0.012)$, and being unemployed $(\beta,-0.09 ; 95 \% \mathrm{CI},-0.17$ to $-0.02 ; \mathrm{p}=0.017$ ) were independently associated with worse QOL (Table 2).

\section{Factors Associated With More Pain Interference}

Current smoking status was the only factor associated with worse pain interference scores $(\beta, 6.0 ; 95 \% \mathrm{CI}, 1.6-11 ; \mathrm{p}=$ 0.008) (Table 2).

\section{Factors Associated With More Anxiety}

After controlling for relevant confounding variables, we found that a primary tumor type with poor prognosis $(\beta$, $3.8 ; 95 \% \mathrm{CI}, 0.37-7.2 ; \mathrm{p}=0.030$ ), and pathologic fracture 
Table 3. Patient-reported outcomes for patients with bone metastases, and comparison with general population values

\begin{tabular}{lllcr}
\hline Questionnaire & Number $(\%)$ & Median (interquartile range) & General population value & $\mathrm{p}$ Value \\
\hline EQ-5D $^{\mathrm{TM}}$ index & $202(100)$ & $0.68(0.40-0.81)$ & 0.85 & $<0.001^{*}$ \\
PROMIS $^{\circledR}$ Pain Interference & $143(71)$ & $65(56-70)$ & 50 & $<0.001^{*}$ \\
PROMIS $^{\circledR}$ Anxiety & $138(68)$ & $53(39-61)$ & 50 & $0.011^{*}$ \\
PROMIS $^{\circledR}$ Depression & $136(67)$ & $48(38-57)$ & 50 & 0.171 \\
\hline
\end{tabular}

*Significant; EQ-5D ${ }^{\mathrm{TM}}=$ EuroQol 5 Dimension Questionnaire; PROMIS ${ }^{\circledR}=$ Patient-Reported Outcomes Measurement Information System.

$(\beta, 6.3 ; 95 \% \mathrm{CI}, 2.5-7.2 ; \mathrm{p}=0.001)$ were independently associated with worse anxiety scores (Table 2 ).

\section{Factors Associated With Depression}

After controlling for relevant confounding variables, we found that pathologic fracture $(\beta, 4.4 ; 95 \% \mathrm{CI}, 0.8-8.0 ; \mathrm{p}=$ $0.017)$, and being single $(\beta, 5.9 ; 95 \% \mathrm{CI}, 0.8-11 ; \mathrm{p}=$ 0.023 ) were independently associated with worse depression scores (Table 2).

\section{Comparison With General US Population Norms}

Patients with metastatic bone disease had worse QOL scores than the US population norm of 0.85 (0.68; range, -0.04 to $1 ; \mathrm{p}<0.001)$, worse PROMIS ${ }^{\circledR}$ Pain Interference scores than the US population norm of 50 (T-score, 65; range, 41-76; $\mathrm{p}<0.001$ ), and worse PROMIS ${ }^{\circledR}$ Anxiety scores than the US population norm of 50 (T-score, 53; range, 39-79; $p=0.011)$. Patients with metastatic bone disease had PROMIS ${ }^{\circledR}$ Depression scores comparable to the US population norm of 50 (T-score, 48; range, 38-73; $\mathrm{p}=0.171)($ Table 3).

\section{Discussion}

QOL plays a crucial role in the treatment of metastatic bone disease [7, 29], and questionnaires that measure QOL can quantify treatment effectiveness and guide clinical decision-making [7, 18, 30]. Previous studies identified risk factors for QOL after medical treatments [8, 25, 28, 29], although it would be useful for clinical decision-making to understand which patients are more prone to have worse QOL regardless of any (prior) treatment. Furthermore, it would be helpful to have normative data for these patients to be able to compare and interpret results of similar patients or patient groups. We found that having a pathologic fracture was independently associated with worse QOL, increased anxiety, and more depression. In addition, younger age, current smoking status, and being unemployed were independently associated with worse QOL. Current smoking status was independently associated with more pain interference. A primary tumor type with poor prognosis was associated with more anxiety, and being single was associated with more depression. Patients with metastatic bone disease reported worse QOL, more pain interference, and more anxiety compared with general population values; their depression scores were not different with the numbers available.

This study has limitations. First, selection bias might have occurred, as we had patient-reported outcomes on only $24 \%$ [202/859] of the eligible patients who presented to our clinic. Nonresponders more often were single, and being single was associated with worse depression scores; if all 859 eligible patients had been included, this could have worsened overall patient-reported outcome scores (especially depression scores), giving larger differences between our sample and US population norms. Second, 56 (28\%) of the 202 patients did not complete a PROMIS ${ }^{\circledR}$ questionnaire, resulting in reduced statistical power for PROMIS $^{\circledR}$ - related outcomes. However, we found no baseline differences between the patients who did and did not complete the PROMIS ${ }^{\circledR}$ questionnaires. Third, questionnaires were completed at different stages of treatment. This cross-sectional survey study represents the breadth of patients with bone metastasis who present to an orthopaedic oncology clinic; some patients filled out the questionnaires during their preoperative visit, whereas others completed the survey after an extensive surgical procedure. The normative data for patient-reported outcomes that we present are not reflections of the effectiveness of certain medical treatments that we provide, and should not be interpreted as such. Fourth, two researchers collected several variables in a retrospective manner (except for the patient-reported outcomes); these variables might have information bias. Another researcher verified a random $10 \%$ sample (21 patients) of the database to detect inconsistencies in all retrospectively collected data; less than $5 \%$ of the data were discrepant, and discrepancies were not consistent within one variable. Therefore we considered this a minor limitation. Fifth, we 
included predominantly white patients from an orthopaedic clinic at a tertiary care hospital in an urban area, therefore our results may not be generalizable to all patients with metastatic bone disease or patients being treated in other settings. Patients who present to our clinic often have an acute or impending fracture or a painful bone lesion; this might result in a sicker patient population compared with patients who do not consult an orthopaedic surgeon [1]. Therefore, our results might show a slight underestimation of QOL for patients with bone metastases. Sixth, we used ICD-9 codes to identify eligible patients and to extract the modified Charlson Comorbidity Index. Coding might have been inaccurate, although we believe this is limited and not of influence on our results. Seventh, outcome measures and explanatory variables were not available for all patients. However, missing data were relatively low (PROMIS ${ }^{\circledR}$ Pain Interference missing in 29\%; PROMIS ${ }^{\circledR}$ Anxiety missing in $32 \%$; PROMIS ${ }^{\circledR}$ Depression missing in $33 \%$; range of percentages of missing data for explanatory variables $1 \%$ to $4 \%$ ). Eighth, the Karnofsky Performance Score was found to be associated with QOL in previous studies [8, 28, 29]. Unfortunately, data on this score were available only for a very small number of patients in our cohort, therefore we could not assess the effect of the performance score on patient-reported outcomes. Ninth, one may advocate that it is inappropriate to include patients with hematologic cancers in this study because these cancers (often) have a better prognosis, which might modify the patients' perception of the disease. We tried to account for this by including the variable "primary tumor type", where hematologic malignancies accounted for 32\% (39/ 121) of the "good prognosis" group. Finally, the normative data on PROMIS ${ }^{\circledR}$ scores we used are not adjusted by age or gender [5]. As we observed in our data, QOL scores may vary based on age: likely, this is also the case in the general population $[15,16,19]$. This limitation might have resulted in an unfair comparison with general population values for PROMIS ${ }^{\circledR}$ questionnaire outcomes. Future studies will need to perform such adjustments, as it seems nearly certain that age and gender would influence patients' PROMIS ${ }^{\circledR}$ scores.

To our knowledge, our findings that patients who were younger, patients who were smokers, patients who were not employed, and patients with pathologic fractures all had poorer QOL, are novel. However, other studies have reported on other risk factors. Choi et al. [8] measured QOL by giving the EQ-5D ${ }^{\mathrm{TM}}$ questionnaire to 922 patients after surgery for metastatic spine disease; predictive factors for postoperative QOL were the preoperative EQ-5D ${ }^{\mathrm{TM}}$ score, the Frankel score, and the Karnofsky performance status. Westhoff et al. [28] collected QOL for 956 patients with breast, prostate, and lung cancers after irradiation for painful bone metastases by giving the Rotterdam Symptom
Checklist, and found that patients with lung cancer had worse QOL scores than patients with prostate and breast cancers. In a study by Wong et al. [29], 396 patients with metastatic bone disease completed the European Organization for Research and Treatment of Cancer Quality of Life Questionnaire Bone Metastases module: a Karnofsky Performance scale greater than 80 (compared with less than 80) and breast or prostate cancer (compared with other cancer types) were associated with better QOL. Rustøen et al. [25] obtained QOL information from 157 oncology outpatients with pain from bone metastasis, using the Multidimensional Quality of Life Scale-Cancer. Depression, social functioning, and physical functioning were the factors associated with QOL.

Having a pathologic fracture was independently associated with worse QOL, more anxiety, and depression. We believe that patients with a pathologic fracture have worse QOL owing to increased pain and disability (as these are components of the EQ-5D ${ }^{\mathrm{TM}}$ ) [24], and more anxiety and depression owing to overall deterioration in health and accompanying death anxiety. This stresses that it is of utmost importance to prevent pathologic fractures, and could serve as a basis for a lower threshold for surgery (such as intramedullary nailing) in patients with impending fractures from metastatic bone lesions.

Patients who were unemployed reported worse QOL, but it is unclear if poor QOL led to unemployment or vice versa. Wong et al. [29] studied 396 patients with bone metastases from various cultures and found that employment status was not associated with QOL. This mixture of cultures might have led to a different contribution of employment status, showing that the extrapolarity of our results to other countries is limited. Current smoking status was associated with worse QOL and more pain interference in our study patients. Although the psychological and physiologic reasons remain unclear, pain and tobacco addiction are theorized to interact in a bidirectional manner [22]; individuals with pain are more likely to be dependent on tobacco, and tobacco addiction is a risk factor for having chronic pain develop. Although the direction of causality is unclear, this interaction gives a positive feedback loop between tobacco abuse and pain, leading to worsening of both conditions [9].

Patients with relatively poor-prognosis tumor types reported more anxiety compared with patients with goodprognosis primary tumor types; this might be attributable to the awareness of a poorer prognosis and fear of death. We broke down this variable further per cancer type and ascertained that patients with lung cancer and adenocarcinoma reported more anxiety compared with patients with breast cancer, multiple myeloma, renal cancer, prostate cancer, or thyroid cancer (Table 4). We also stratified for pathologic fracture, as this also was a risk factor; these 
Table 4. PROMIS ${ }^{\mathbb{R}}$ Anxiety t-scores with $95 \%$ CIs, stratified for most common primary tumor types, and pathologic fracture

\begin{tabular}{|c|c|c|c|c|c|c|c|c|}
\hline \multirow[t]{2}{*}{ Patient group } & \multicolumn{2}{|c|}{ Poor-prognosis tumors* } & \multicolumn{5}{|c|}{ Good-prognosis tumors* } & \multirow[b]{2}{*}{$\begin{array}{l}\text { All } \\
\text { patients } \\
\mathrm{n}=138\end{array}$} \\
\hline & $\begin{array}{l}\text { Lung } \\
\text { carcinoma } \\
n=26\end{array}$ & $\begin{array}{l}\text { Adenocarcinoma } \\
\mathrm{n}=5\end{array}$ & $\begin{array}{l}\text { Breast } \\
\text { carcinoma } \\
\mathrm{n}=23\end{array}$ & $\begin{array}{l}\text { Multiple } \\
\text { myeloma } \\
\mathrm{n}=22\end{array}$ & $\begin{array}{l}\text { Renal cell } \\
\text { carcinoma } \\
\mathrm{n}=19\end{array}$ & $\begin{array}{l}\text { Prostate } \\
\text { carcinoma } \\
\mathrm{n}=9\end{array}$ & $\begin{array}{l}\text { Thyroid } \\
\text { carcinoma } \\
\mathrm{n}=5\end{array}$ & \\
\hline $\begin{array}{l}\text { All patients }(\mathrm{n}= \\
\text { 138) }\end{array}$ & $54(49-61)$ & $57(54-63)$ & $53(46-63)$ & $51(39-62)$ & $51(39-63)$ & $49(39-51)$ & $49(39-51)$ & $\begin{array}{c}53(39- \\
61)\end{array}$ \\
\hline \multicolumn{9}{|l|}{$\begin{array}{c}\text { Pathologic } \\
\text { fracture }\end{array}$} \\
\hline No $(n=100)$ & $51(39-57)$ & $56(52-30)$ & $51(39-61)$ & $54(39-63)$ & $46(39-57)$ & $49(43-53)$ & $49(39-51)$ & $\begin{array}{c}51(39- \\
57)\end{array}$ \\
\hline Yes $(n=38)$ & $61(53-63)$ & $74(74-74)$ & $57(51-63)$ & $50(46-58)$ & $66(63-69)$ & $39(39-39)$ & - & $\begin{array}{c}58(49- \\
63)\end{array}$ \\
\hline
\end{tabular}

The most common primary tumor types are included $(\mathrm{n}>5)$; *based on study by Katagiri et al. [17], primary tumors were categorized as tumors with a relatively good prognosis (breast, kidney, prostate, thyroid, myeloma, and lymphoma), and tumors with a relatively poor prognosis (all other tumor types).

normative data can be used to compare and interpret results of similar patients or patient groups. Furthermore, awareness of anxiety and referral for psychological counseling in patients with poor-prognosis tumor types is recommended.

Studies show that in the general population older age is associated with worse QOL scores [15, 16, 19], whereas in our study population younger age was associated with worse QOL. We speculate that younger patients may be more traumatized when receiving a diagnosis of metastatic disease (it comes more unexpectedly), have greater responsibilities to their family and community, and have more life goals compared with older patients [20, 27, 32]. Like in our study, previous studies showed an association between being married and better QOL [3, 11, 29]. Goodwin et al. [13] suggested that married patients with cancer may have a better QOL because they are diagnosed at an earlier stage, they may show better response to treatment, and because they benefit from the social support and care-taking skills of the spouse.

To our knowledge, this is the first study comparing QOL, pain interference, anxiety, and depression scores for patients with bone metastases with general population values. Previously, patients with any type of cancer were found to have similar QOL compared with a general US adult population sample [4]. In light of this, we questioned why patients with bone metastases from our cohort reported worse QOL. Patients with bone metastases might have more pain, reduced mobility, impaired role functioning, and reduced physical performance [2]. Pain interference scores were higher compared with US population values; this can be explained by the painful conditions (pathologic fractures, painful bone lesions) that are the most common reasons for presenting to an orthopaedic surgeon [1]. Furthermore, we believe that patients had higher anxiety scores owing to fear of pain or to death anxiety [26]. Death anxiety is common in patients with advanced cancer and has been associated with generalized anxiety [12, 21, 26]. Surprisingly, depression scores were comparable to general population values. Previous studies explained this phenomenon as emotional and spiritual adaptation, and taking the cancer diagnosis in consideration when evaluating health status [21, 31].

Physicians can use the factors we associated with poorer scores for QOL, pain interference, anxiety, and depression to anticipate which patients might need additional psychosocial support during treatment for metastatic bone disease. Furthermore, our normative data can be used to compare and interpret results of other patients or patient groups for future studies. Our study results support that impending pathologic fractures should be treated promptly (perhaps by intramedullary nailing) to prevent further deterioration in QOL, anxiety, and depression. Every type of cancer that metastasizes to the bone has a different disease course, treatment, and prognosis; therefore, it would merit further study to reproduce our study in cancer-specific groups, to identify more accurate factors accounting for variation in patient-reported outcomes.

\section{References}

1. Agarwal MG, Nayak P. Management of skeletal metastases: an orthopaedic surgeon's guide. Indian J Orthop. 2015;49:83-100.

2. Barton MB, Dawson R, Jacob S, Currow D, Stevens G, Morgan G. Palliative radiotherapy of bone metastases: an evaluation of outcome measures. J Eval Clin Pract. 2001;7:47-64.

3. Broeckel JA, Jacobsen PB, Balducci L, Horton J, Lyman GH. Quality of life after adjuvant chemotherapy for breast cancer. Breast Cancer Res Treat. 2000;62:141-150.

4. Brucker PS, Yost K, Cashy J, Webster K, Cella D. General population and cancer patient norms for the Functional 
Assessment of Cancer Therapy-General (FACT-G). Eval Health Prof. 2005;28:192-211.

5. Cella D, Riley W, Stone A, Rothrock N, Reeve B, Yount S, Amtmann D, Bode R, Buysse D, Choi S, Cook K, Devellis R, DeWalt D, Fries JF, Gershon R, Hahn EA, Lai JS, Pilkonis P, Revicki D, Rose M, Weinfurt K, Hays R; PROMIS Cooperative Group. The Patient-Reported Outcomes Measurement Information System (PROMIS) developed and tested its first wave of adult self-reported health outcome item banks: 2005-2008. J Clin Epidemiol. 2010;63:1179-1194.

6. Charlson ME, Pompei P, Ales KL, MacKenzie CR. A new method of classifying prognostic comorbidity in longitudinal studies: development and validation. $J$ Chronic Dis. 1987;40:373-383.

7. Cheng EY. Prospective quality of life research in bony metastatic disease. Clin Orthopaed Relat Res. 2003;415(suppl)S289-297.

8. Choi D, Fox Z, Albert T, Arts M, Balabaud L, Bunger C, Buchowski JM, Coppes MH, Depreitere B, Fehlings MG, Harrop J, Kawahara N, Martin-Benlloch JA, Massicotte EM, Mazel C, Oner FC, Peul W, Quraishi N, Tokuhashi Y, Tomita K, Verlaan JJ, Wang M, Crockard HA. Prediction of quality of life and survival after surgery for symptomatic spinal metastases: a multicenter cohort study to determine suitability for surgical treatment. Neurosurgery. 2015;77:698-708; discussion 708 .

9. Ditre JW, Brandon TH, Zale EL, Meagher MM. Pain, nicotine, and smoking: research findings and mechanistic considerations. Psychol Bull. 2011;137:1065-1093.

10. Fryback DG, Dunham NC, Palta M, Hanmer J, Buechner J, Cherepanov D, Herrington SA, Hays RD, Kaplan RM, Ganiats TG, Feeny D, Kind P. US norms for six generic health-related quality-of-life indexes from the National Health Measurement study. Med Care. 2007;45:1162-1170.

11. Ganz PA, Lee JJ, Siau J. Quality of life assessment: an independent prognostic variable for survival in lung cancer. Cancer. 1991;67:3131-3135.

12. Gonen G, Kaymak SU, Cankurtaran ES, Karslioglu EH, Ozalp E, Soygur $\mathrm{H}$. The factors contributing to death anxiety in cancer patients. J Psychosoc Oncol. 2012;30:347-358.

13. Goodwin JS, Hunt WC, Key CR, Samet JM. The effect of marital status on stage, treatment, and survival of cancer patients. JAMA. 1987;258:3125-3130.

14. Harris PA, Taylor R, Thielke R, Payne J, Gonzalez N, Conde JG. Research electronic data capture (REDCap): a metadata-driven methodology and workflow process for providing translational research informatics support. J Biomed Inform. 2009;42:377-381.

15. Hjermstad MJ, Fayers PM, Bjordal K, Kaasa S. Using reference data on quality of life: the importance of adjusting for age and gender, exemplified by the EORTC QLQ-C30 (+3). Eur $J$ Cancer. 1998;34:1381-1389.

16. Holzner B, Kemmler G, Cella D, De Paoli C, Meraner V, Kopp M, Greil R, Fleischhacker WW, Sperner-Unterweger B. Normative data for functional assessment of cancer therapy: general scale and its use for the interpretation of quality of life scores in cancer survivors. Acta Oncol. 2004;43:153-160.

17. Katagiri H, Takahashi M, Wakai K, Sugiura H, Kataoka T, Nakanishi K. Prognostic factors and a scoring system for patients with skeletal metastasis. J Bone Joint SurgBr. 2005;87:698-703.
18. Lipscomb J, Gotay CC, Snyder CF. Patient-reported outcomes in cancer: a review of recent research and policy initiatives. $C A$ Cancer J Clin. 2007;57:278-300.

19. Michelson H, Bolund C, Nilsson B, Brandberg Y. Health-related quality of life measured by the EORTC QLQ-C30: reference values from a large sample of Swedish population. Acta Oncol. 2000;39:477-484.

20. Mor V, Allen S, Malin M. The psychosocial impact of cancer on older versus younger patients and their families. Cancer. 1994;74(7 suppl):2118-2127.

21. Parker PA, Baile WF, de Moor Cd, Cohen L. Psychosocial and demographic predictors of quality of life in a large sample of cancer patients. Psychooncology. 2003;12:183-193.

22. Parkerson HA, Zvolensky MJ, Asmundson GJ. Understanding the relationship between smoking and pain. Expert Rev Neurother. 2013;13:1407-1414.

23. Quan H, Li B, Couris CM, Fushimi K, Graham P, Hider P, Januel JM, Sundararajan V. Updating and validating the Charlson comorbidity index and score for risk adjustment in hospital discharge abstracts using data from 6 countries. Am J Epidemiol. 2011;173:676-682.

24. Rabin R, de Charro F. EQ-5D: a measure of health status from the EuroQol Group. Ann Med. 2001;33:337-343.

25. Rustøen T, Moum T, Padilla G, Paul S, Miaskowski C. Predictors of quality of life in oncology outpatients with pain from bone metastasis. J Pain Symptom Manage. 2005;30:234-242.

26. Tong E, Deckert A, Gani N, Nissim R, Rydall A, Hales S, Rodin $\mathrm{G}$, Lo $\mathrm{C}$. The meaning of self-reported death anxiety in advanced cancer. Palliat Med. 2016;30:772-779.

27. Wan GJ, Counte MA, Cella DF. The influence of personal expectations on cancer patients' reports of health-related quality of life. Psychooncology. 1997;6:1-11.

28. Westhoff PG, de Graeff A, Monninkhof EM, Pomp J, van Vulpen M, Leer JW, Marijnen CA, van der Linden YM, Dutch Bone Metastasis Study Group. Quality of life in relation to pain response to radiation therapy for painful bone metastases. Int $J$ Radiat Oncol Biol Phys. 2015;93:694-701.

29. Wong E, Chow E, Zhang L, Bedard G, Lam K, Fairchild A, Vassiliou V, Alm El-Din MA, Jesus-Garcia R, Kumar A, Forges F, Tseng LM, Hou MF, Chie WC, Bottomley A. Factors influencing health related quality of life in cancer patients with bone metastases. J Palliat Med. 2013;16:915-921.

30. Wu J, Zheng W, Xiao JR, Sun X, Liu WZ, Guo Q. Health-related quality of life in patients with spinal metastases treated with or without spinal surgery: a prospective, longitudinal study. Cancer. 2010;116:3875-3882.

31. Wyatt G, Sikorskii A, Tamkus D, You M. Quality of life among advanced breast cancer patients with and without distant metastasis. Eur J Cancer Care (Engl). 2013;22:272-280.

32. Zimmermann C, Burman D, Swami N, Krzyzanowska MK, Leighl N, Moore M, Rodin G, Tannock I. Determinants of quality of life in patients with advanced cancer. Support Care Cancer. 2011;19:621-629. 